\title{
Anabases
}

ANABASES Traditions et réceptions de l'Antiquité

$8 \mid 2008$

Varia

\section{Loren T. STUCKENBRUCK, Stephen C. BARTON,} Benjamin G. WOLD, (éd.), Memory in the Bible and Antiquity

\section{Corinne Bonnet}

\section{OpenEdition}

\section{Journals}

Édition électronique

URL : http://journals.openedition.org/anabases/270

DOI : 10.4000/anabases.270

ISSN : 2256-9421

\section{Éditeur}

E.R.A.S.M.E.

\section{Édition imprimée}

Date de publication : 1 octobre 2008

Pagination : 311-312

ISSN : 1774-4296

\section{Référence électronique}

Corinne Bonnet, "Loren T. stuckendruck, Stephen C. barton, Benjamin G. wold, (éd.), Memory in the Bible and Antiquity ", Anabases [En ligne], 8| 2008, mis en ligne le 01 juillet 2011, consulté le 22 septembre 2020. URL : http://journals.openedition.org/anabases/270 ; DOI : https://doi.org/10.4000/anabases. 270

Ce document a été généré automatiquement le 22 septembre 2020

(c) Anabases 


\title{
Loren T. STUCKENBRUCK, Stephen C. BARTON, Benjamin G. WOLD, (éd.), Memory in the Bible and Antiquity
}

\author{
Corinne Bonnet
}

\section{RÉFÉRENCE}

Loren T. STUCKENBRUCK, Stephen C. BARTON, Benjamin G. wold, (éd.), Memory in the Bible and Antiquity, The Fifth Durham-Tübingen Research Symposium (Durham, September 2004), Wissenschaftliche Untersuchungen zum Neuen Testament, 212, Tübingen, Mohr Siebeck, 2007, $394 \mathrm{p}$.

177,50 dollars / ISBN 978-3-16-149251-8.

1 Seize contributions explorent le concept de mémoire dans la Bible et dans l'Antiquité en général. La place des études bibliques et judaïques dans ce volume est tout à fait dominante : les essais proposés touchent au Deutéronome, à la poésie hébraïque, aux livres des Maccabées, à Qumran, à Flavius Josèphe, aux Évangiles et à la tradition christologique en général. La mémoire, le souvenir et la commémoration, il faut l'avouer, constituent un ressort structurel au sein du texte biblique qu'il est bienvenu d'explorer. La tradition judéo-chrétienne, en effet, accorde à la dimension temporelle une attention toute particulière. C'est dans l'histoire que le rapport des hommes avec Dieu se forme et se joue. C'est aussi en référence à des événements historiques que l'identité des Hébreux et des Juifs se construit. Dans le rituel, le rappel du passé, sa mise en scène, sa commémoration revêtent une importance cruciale. Que l'on songe aux généalogies, au calendrier rituel, aux pratiques liturgiques, au processus d'élaboration des règles de vie ou de transmission des écrits sacrés, la mémoire est toujours au centre $\mathrm{du}$ vécu et du pensé. Normative, la mémoire est aussi une matière éminemment subjective, voire polémique. Chacun se l'approprie, la vit, la travaille à sa façon. L'exercice de la mémoire est forcément sélectif et orienté, qu'il s'agisse du niveau 
individuel ou collectif. Les enjeux de ce volume sont donc considérables et fort bien définis en Introduction. Les différentes contributions apportent sur la problématique générale divers éclairages d'un grand intérêt.

On y envisage à la fois la mémoire écrite (" narrative ») et la mémoire orale, celle des événements, comme l'Exode, la conquête de Canaan ou la destruction du Temple et l'Exil, et celle des personnages, comme Moïse, Salomon ou le «Teacher of Righteousness» qui est au cœur des textes qumraniens. Quelques contributions envisagent un parallèle entre la mémoire juive et celle des Grecs; de ce point de vue le Contre Apion de Flavius Josèphe constitue un terrain d'enquête fort intéressant puisqu'il s'efforce de convaincre les Grecs et les Romains du caractère immémorial du passé juif. Dans la section consacrée au Nouveau Testament, on voit à l'œuvre le processus de « réminiscence » qui fait de Jésus le Messie annoncé dans l'Ancien Testament, celui qui accomplit les promesses du passé, mais en même temps, celui dont la mémoire, sans cesse actualisée par le rite de l'eucharistie, fonde une nouvelle Alliance. Mais, dans la mémoire même du Christ, des contradictions apparaissent d'un Évangile à l'autre, que tel ou tel essai envisage et explique. Entre Luc et Jean, par exemple, il est clair que le concept de "mémoire " n'opère pas de la même façon, par delà même les évidentes différences de mise en forme littéraire.

En définitive, l'ensemble de ces contributions, d'une excellente facture, montre à quel point le recours à la mémoire est un enjeu stratégique, entre passé, présent et futur. Il a une fonction structurante et identitaire dans les sociétés antiques. Peu de place est faite, dans ce traitement, au concept de « lieu de mémoire " pourtant opératoire à coup sûr dans la culture biblique : que l'on songe à l'Égypte, au Sinaï, à Babylone ou à Jérusalem. Cela dit, le volume mérite toute l'attention des spécialistes. Il s'adresse essentiellement à ceux qui travaillent sur Israël, mais les habitués du monde grec et romain y trouveront des analyses stimulantes pour leur propre domaine. Un copieux index en rend l'utilisation aisée.

\section{AUTEURS}

\section{CORINNE BONNET}

Université de Toulouse II

cbonnet@sfr.fr 